\title{
Political-Economic Coalition Among Entrepreneurs, Professionals, and Cadres in Guangdong, China
}

\author{
by Chau-kiu Cheung and Eileen Yuk-ha Tsang \\ City University of Hong Kong
}

Sociological Research Online, 20 (4), 14

$<$ http://www.socresonline.org.uk/20/4/14.html>

DOI: $10.5153 /$ sro.3798

Received: 30 Mar 2015 | Accepted: 24 Aug 2015 I Published: 30 Nov 2015

\begin{abstract}
As entrepreneurs, professionals, and cadres constitute the middle tier in China, they exhibit extravagance, gifting, and the pursuit of privileges. Particularly, privileges are likely to stem from political-economic coalition within the middle tier. The coalition is also likely to favor the preservation of the political structure. All these features of the middle tier need substantiation with qualitative data. The study gleaned the data from personal interviews with 59 entrepreneurs, professionals, and cadres in Guangdong, China. Results illustrate extravagance, political-economic coalition, privileges, and political preservation espoused by the middle tier. These results identify an investment theory to reflect the preservation of investment in political-economic coalition in order to reap privileges to afford extravagance in the middle tier. The results imply that political reform in China hinges on the erosion of the exchange of privileges in the coalition.
\end{abstract}

Keywords: Social Class, Political-Economic Coalition, Conspicuous Consumption, Middle Tier

\section{Introduction}

1.1 Research theory and research manifest a need for elaborating the cultural, economic, and political orientations and practices of the middle tier in transitioning society such as China (Goodman 2014; Qian 2014). The middle tier consists of entrepreneurs, professionals, and cadres across private and public sectors in China (Gerth 2011; Hanley and Treiman 2005). Entrepreneurs refer to those who inaugurate their businesses, professionals are those using their expertise in employed work, and cadres are those wielding administrative power in government agencies (Walder 2003). Entrepreneurs, professionals, and cadres are likely to form political-economic coalitions through patron-client relations to reap mutual benefits (Ma and Cheng 2010; Tsai and Dean 2014). To obtain the benefits, a possible task of the coalition is preserving political and economic frameworks and arrangements that sustain the vested interests (Lee and Zhang 2013; N.Wang 2012). The interests concerned are likely the constituents' maintenance of privileges and extravagant living (Gerth 2011). Such relationships among extravagance, coalition, and preservation are all practically and ethically significant, in view of their connotations for collusion, cronyism, bribery, unfairness, and wastage (Himes 2007; Mele 2010). Some works have displayed the role of the coalition in sustaining business and political operations (Chen 2010; Millington et al. 2006; Su et al. 2006; Tsai and Dean 2014). Nevertheless, there is still a need for an integrated illustration of the cultural and economic bases and the political implications of the coalition. For the illustration, the present study presents down-to-earth qualitative data from the reflective reports of entrepreneurs, professionals, and cadres from the province of Guangdong, China. These data, based on open-ended responses from the middle-tier members, turn out to reveal a grounded theory about the political-economic coalition.

\section{Chinese Context}


This culture, nevertheless, is pluralistic or multifaceted (Anagnost 2008; Crabb 2010). A significant facet of the culture transpires in the middle tier (Donald and Zheng 2009). As constituents of the middle tier, many entrepreneurs become parvenus who enjoy extravagant living and sharpen wealth inequality (Xiang and Li 2001). Initially, many entrepreneurs turned from cadres due to the privatization of state assets Gerth 2011). As time goes, entrepreneurs still maintain close connections with cadres to generate benefits to both parties (Ma and Cheng 2010). Meanwhile, economic growth evolves and entails a class of professionals, who also benefit from their connections with cadres (Crabb 2010; Zheng 2003). Cadres, who hold prestigious positions in authoritarian administration in China, are capable of offering particularistic and tremendous benefits to those in the private sector (Lin and Wu 2009; Walder 2003). Therefore, the coalition, collusion, or clique involving entrepreneurs, professionals, and cadres is unsurprising (Tian et al. 2006; Yao 2002).

2.2 The Chinese middle-tier comprises cadres, professionals, or entrepreneurs, who enjoy decent incomes (Goodman 2014; Y. Guo 2012). Such a middle tier is not a middle class in the conventional, materialist sense, which precludes entrepreneurs because of their possession of capital (Ebert and Zavarzadeh 2008). Chinese entrepreneurs, as well as cadres and professionals, albeit powerful economically and politically, are not powerful enough to make them the ruling class (Todorova 2013). Notably, the cadres form bureaucratic factions within an authoritarian structure to appropriate their particular privileges (Paltemaa 2007). Moreover, Chinese entrepreneurs, professional, and cadres are unlikely to espouse common class-consciousness to uphold common actions to safeguard their common interests, in view of public discourse that downplays the legitimacy and role of class (Y.Guo 2012).

2.3 The political-economic coalition is inclined to withhold the democratic political reform that may be detrimental to its vested interest (Chen 2010; Tsai and Dean 2014). The political reform, nevertheless, is imperative to realize the policy, representativeness, and legitimacy of the Chinese state (Chai and Song 2013; Tsai and Dean 2014). That is, the state aspires to enact the reform to represent the masses and the middle tier particularly and thus advance economic performance. Election and decentralization are therefore the content of the reform. Nevertheless, the reform proceeds prudently and gradually in a bottom-up way (Tsai and Dean 2014). The reform is also susceptible to support and resistance from various coalitions within and across political ranks.

2.4 Guangdong is a crucial place for the study of China, as it is the powerhouse of development in China (Rubini and Berbieri 2013; Ruffier 2010; Yu, H. 2014). That is, Guangdong is a coastal province that attracts investments from Hong Kong and foreign countries to establish its factories for the world. Guangdong is essentially the testing ground of the opening policy and economic reform in China. Initially, Guangdong also offers cheap labor and good infrastructures to facilitate the agglomeration of factories. The solid base of economic development enables local entrepreneurship and professionalization there. Consequently, Guangdong enjoys rapid economic growth through foreign and domestic investments. Nevertheless, wages and various political-economic discontents are rising to put a stress on the sizable and sophisticated political system in Guangdong. The stasis and flow of the political-economic coaltion there are therefore of concern, particularly when Guangdong is a longstanding window for learning between China and the outside world.

\section{Middle-tier Life}

3.1 Middle-tier members afford to live in an extravagant way by their incomes from work and politicaleconomic coalition (Chen 2010; Tsai and Dean 2014). They aspire to emulate those of the leisure class to spend on expensive goods and activities through conspicuous consumption (Wang and Chen 2004). Moreover, middletier consumers are conscious of the style and quality of commodities in order to highlight their lifestyle (Shipman 2004). The style and quality also characterize gifts exchanged in political-economic coalition (X.Qi 2013). Accordingly, gifting is functional to maintaining a coalition, as it conforms to the norm of reciprocity (Ashworth 2013; Mallard 2011).

3.2 Despite their common display of extravagant living (Gerth 2011; Goodman 2014), middle-tier members do not need to share a common identity to defend their collective interest (Ma and Cheng 2010). They instead are likely to sustain personal, particularistic ties among selected constituents in order to procure particularistic privileges (Guo and Miller 2010). That is, each entrepreneur, professional, or cadre pursues interests competitively through a personal coalition rather than acting collectively to acquire and homogenize collective benefits. Notably, these benefits to the middle tier through political-economic coalition are never predestined, unlike those from an enduring caste, which inherits privileges across generations (Weede 2010). The middle tier, composed of the bureaucrats and entrepreneurs, strives to perpetuate their privileges to forge a caste society (Xie and Wu 2008). 


\section{Investment Theory about the Political-economic Coalition}

4.1 A serendipitous finding emerging from the report of middle-tier Chinese is the identification of investment theory about political-economic coalition. The theory holds that investment is the key maintaining relationships among extravagant living, privilege acquisition, and preserving the political structure. Beforehand, the view of the middle tier toward political reform is uncertain, given divergent possibilities. One possibility is for the middle tier to disfavor the democratic political reform in order to preserve the interests of the constituents (Y. Guo 2012; Todorova 2013). Another, contradictory possibility is for the middle tier to activate the political reform in order to upgrade status, power, and benefits for the constituents (H. Li 2006; F. Shi 2014). In this connection, the middle tier has the desire and capability to maximize freedom and opportunities (Song and Lee 2010). This is the argument of social mobilization theory, which states that the middle tier is well prepared to hold the greatest aspiration and interest in overthrowing the ruling tier (Huntington 1968; Zimmermann 1983).

4.2 A way to resolve the uncertainty about the view of the middle tier toward political preservation is the recognition about political-economic coalition within the tier. The coalition means the political-economic convergence of interest in preserving the political structure (Niederberger 2005). Furthermore, as a part of the political structure, the coalition is predisposed to preserve the structure (Norris 2011). Conversely, the split between the private economic sector and the state political sector is a seed of political-economic conflict and political change (Opp 2009). When the two sectors are antagonistic, urges for political reform would be great (Fumagalli 2007; Wieloch 2002).

4.3 A drive for the middle tier to forge the political-economic coalition is the interest in sustaining extravagant living. In the first place, the constituents of the Chinese middle tier in both private and public sectors desire and relish extravagant living (Goodman 2014; Y. Guo 2012). As extravagant living depends on economic resources, the coalition would be a basis to reap the resources. Such dependence rests on exchange theory, which posits that the coalition evolves from exchange that offers benefits to exchange partners (Skopek et al. 2011; Molm 2008). In this juncture, the mutual benefits happen because of the comparative advantage of each partner to gratify each other's unique need. A way for the maintenance of mutual benefits is gifting, which can be functional to relation building (Ashworth 2013; Mallard 2011). Gifting involves such features of obligation to reciprocation, communication, conformity, dependency, and inalienability such that a gift is personally meaningful and memorable.

4.4 In sum, a vision emerges to suggest extravagant living as a drive to political-economic coalition within the Chinese middle tier to preserve the political structure. This vision mirrors investment theory applied to explain efforts to maintain citizenship, social solidarity, social capital, and human capital through civic engagement and mutual aid, (Glaeser et al. 2002; Sawada and Lokshin 2009; Prouteau and Wolff 2008). The vision becomes evident with reference to qualitative data provided by the constituents of the middle tier.

\section{Method}

5.1 The study applied ethnography to collect qualitative data, through personal, in-depth interviews with 59 middle-tier constituents, entrepreneurs, professionals, or cadres, located in six cities of Guangdong Province, China. Criteria for locating them through referral were (1) a minimum per-capita monthly income of $¥ 9,000$ (US\$1,285), (2) a minimum liquid asset of $¥ 300,000$ (US\$4,285), (3) a minimum education of postsecondary level, (4) urban residency, and (5) ownership of a house or a car by direct payment or mortgage. The constituents were 31 entrepreneurs, 17 professionals in educational, medical, or engineering fields, and 11 cadres of government agencies (see Table 1). They were 50 men and 9 women aged between 25 and 60 years.

Table 1. Distribution (\%) of interviewees 


\begin{tabular}{llcccc}
\hline & Age & Cadre & Entrepreneur & Professional & All \\
\hline Female & $25-34$ & 0 & 1 & 5 & 6 \\
& $35-44$ & 1 & 0 & 0 & 1 \\
& $45-60$ & 2 & 0 & 0 & 2 \\
\hline Male & All & 3 & 1 & 5 & 9 \\
& $25-34$ & 1 & 6 & 6 & 13 \\
& $35-44$ & 1 & 10 & 3 & 23 \\
& $45-60$ & 6 & 14 & 3 & 50 \\
\hline All & All & 8 & 30 & 12 & 19 \\
& $25-34$ & 1 & 7 & 11 & 25
\end{tabular}

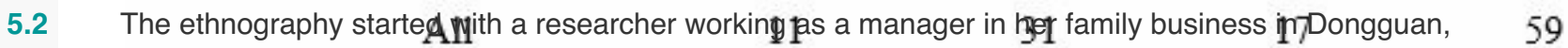
which was a factory city in Guangdong Province. Through her job, she managed to maintain contact with five local entrepreneurs, protessionals, and cadres. Using a snowball sampling procedure, she extended contact with 54 entrepreneurs, professionals, and cadres in Guangdong Province. Eventually, she interviewed all the 59 middle-tier members in formal-business and informal-leisure occasions in a year. Based on the ethnographic procedures of sustaining rapport and social relationships with the interviewees, the interviews were able to elicit credible data (Griffin and Bengry-Howell 2008). Accordingly, the ethnography involved getting familiar with the middle-tier members through socializing or leisure activities and prolonged sharing in natural settings in order to elicit authentic ideas through repeated interviews.

5.3 The interviews proceeded in places chosen by the interviewees to ask about interviewees' experiences, feelings, and expectations about their life, particularly its economic and political aspects. That is, the interviews asked the interviewees to describe what they did, felt and expected about their life and relationships with government or politics. Each interview had four core questions, respectively about the interviewee's general image about the middle tier, and particular views about the functions, contributions, and identity of the middle tier. These questions sought open-ended responses from the interviewees. Essentially, the interviews operated interactively and flexibly to elicit the greatest volume of pertinent ideas for the questions.

5.4 Transcribed ideas from the interviews were accessible electronically to facilitate the systematic analysis with reference to the grounded theory approach. The approach started with open coding, which iteratively coded all detectable ideas into dual codes, consisting of pairs of categories and concepts (Strauss and Corbin 1998). This coding adhered to the constant comparison method to ensure conciseness and consistency (Hood 2007). The next step was axial coding, which identified linkages among the coded categories to build a structure to encompass the codes. Essentially, this step differentiated antecedents, mediators, consequences, and their links. The third step of selective coding extracted the theoretically thoughtful and enlightening portion of the structure to weave a story for sustaining a grounded theory.

\section{Results}

6.1 A grounded theory about investment in the formation of the political-economic coalition evolved from the analysis of qualitative data provided by the middle-tier interviewees (see Figure 1). The investment theory principally elaborated the successive influences from extravagance to political-economic coalition and preservation of the political structure. Accordingly, the theory revealed the penchant of Chinese middle-tier 
members for preserving the political environment in order to continue building and leveraging social capital to consolidate economic capital for sustaining cultural capital. This rested on its commonality among entrepreneurs, cadres, and professionals in the middle tier and its distinctiveness from the other groups. That is, members in the middle tiers expressly maintained a life that emphasized conspicuous and luxury consumption and demeaned the practices of the lower tier. As such, they forged and adhered to a norm of extravagance and its preservation. The following are details about extravagance, political-economic coalition, and political preservation, with reference to quotes from interviews (identified by their aliases, ages, and occupations).

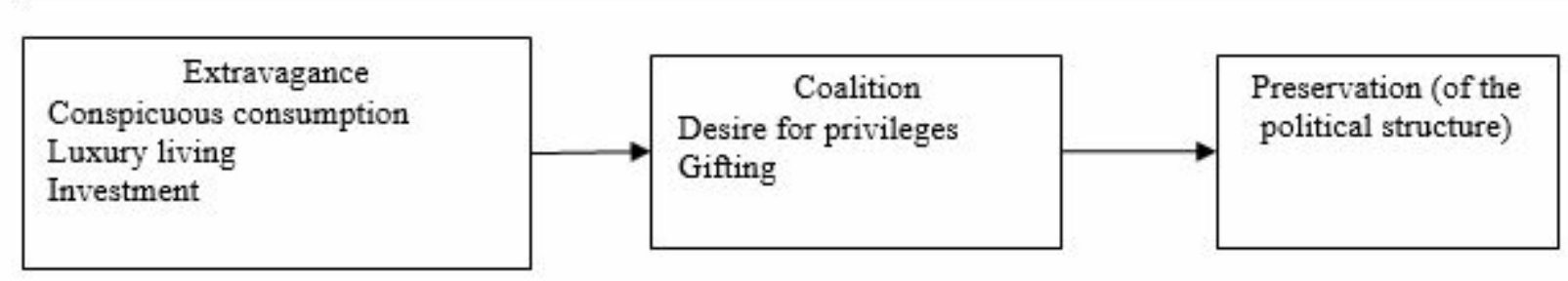

Figure 1. Investment theory of political-economic coalition

\section{Extravagance}

7.1 Extravagance, as reflected from interviewees' words, happened in expensive purchase or consumption of goods, housing, and activities such as traveling. It manifested the desire for quality of life such as artistic value, and world-famed brands. The desire reflected the emphasis of the middle tier on distinctiveness, privilege, and excellence over other tiers. Some original words are as follows.

Quality of life is very important. I want more than a simple shelter. I'm looking to experience the art of living. A clubhouse is a must-have item for me. (Raymond, 30, professional)

Extravagance, according to interviewees, naturally happened in daily life such as in the form of gambling and social engagement. By regarding commodity price as a cue for spending, extravagance was a recognized feature of the middle tier. Commonality in the tier was a quality to make extravagance exemplary. The extravagance, nevertheless, did not need to be socially functional, as in comparison with others. Moreover, extravagance such as losing even a sum of money was forgettable to the entrepreneur, as indicated in the following quote.

\footnotetext{
A business dinner party can count as a social engagement, and typically costs $¥ 7,000$ (US $\$ 1,025$ or $£ 708$ ) or $¥ 8,000$ (US $\$ 1,171$ or $£ 809$ ) each time. I don't mean to show off. I don't have a sense of superiority. I prefer to spend money on buying houses or cars. If I gambled away $¥ 10,000$ [US $\$ 1,463$ or £999] betting on football, I'd forget about this the next day. This is a common attitude for many people of the Chinese new middle class. (Uncle Fong, 48, entrepreneur)
}

Extravagance was further composed of conspicuous consumption, luxury living, and investment. The components reflected some different motives and forms of extravagance.

\section{Conspicuous consumption}

7.3 Conspicuous consumption, as reflected by interviewees' remarks, indicated extravagance for upgrading or at least affirming the consumer's status. Such consumption would involve a comparison with other people, showing off the status, and/or presenting a good image to others. These features indicated the need for being genteel and attractive in the middle tier to demonstrate material worth and social status. The practice would be lucrative, according to the following quote.

\footnotetext{
I prefer an iPhone or Samsung phone, car or suit from a brand such as Prada, since I can show off when I meet my clients. Although I am not a boss, I need to be presentable and dress stylishly when I meet my clients in order to earn a bonus and commission. (Tong, 32, professional)
}

7.4 The real famous brand was important for conspicuous consumption, according to interviewees. This meant that conspicuous consumption in the middle tier would not involve faked brands. As such, conspicuous consumption was usable to convey an image of genuine status, quality, connoisseurship, and even wisdom in spending. This feature illustrated that the middle tier desired to enjoy the best image and quality from 
consumption. A professional gave the following remark.

I think if entrepreneurs want to attract business investments in China, they need to bring high status branded goods to Guangdong. They need to show us the certificate of each item together with its product code. This can guarantee I won't buy any counterfeit goods. I feel disgusted when I find that I have spent a great deal of money on fakes. (Ivy, 26, professional)

\section{Luxury living}

Luxury living, as reflected by interviewees' comments, disclosed the desire for comfort, fulfillment, and quality life. It was not just a by-product of social comparison, status affirmation, or showing off a classy image. This feature illustrated that the middle tier was knowledgeable and choosy in maximizing quality of life. The knowledge was an integral quality of the middle tier. Practical satisfaction of desire was a basis for extravagance for luxury living, as clarified by the following quote.

\footnotetext{
My home, where I live with my wife and two daughters, occupies 150 square meters. I spent about $¥ 1$ million [US $\$ 146,316$ or $£ 99,796$ ] furnishing it. The house isn't just for living, but provides a tasteful environment where my family and I can have a high quality of life. I didn't have it designed for luxury but, rather, with a taste for the modern. I bought materials from France, Italy, and other European countries. I simply pursued my tastes. I don't like to follow popular Chinese furnishing styles, which I regard as tasteless and without character. We wanted to have our own swimming pool and now only the residents have the privilege of gaining access to it. (Tsang, 37, entrepreneur)
}

\section{Investment}

Investment, based on interviewees' reflection, meant to support the long-term development of their families. This investment was sizable in order to furnish a secure base for reaping future rewards. The investment appeared to be necessary to avoid many risks found in Chinese society. This feature reflected the wish of the middle tier to maintain perpetual achievements across generations, and essentially the long-term planning and perspective. The following quote gives the argument for the extravagant investment.

\footnotetext{
I don't think I spoil my son. I just want him to enjoy his studies without worrying about money. I am proud of him since I know that whatever he achieves will be good for us as a family. I pay for his tuition fees, around $¥ 110,000$ (US $\$ 14,641$ or $£ 11,134$ ) per year. I provide him with $¥ 5,000$ (US $\$ 732$ or $£ 506$ ) for his monthly expenditure and I pay for his accommodation [around US\$800/£400 per month]. I don't want him to get distracted from his studies. (Uncle Fang, 49, cadre)
}

7.7 Notably, investment in children's schooling was expensive. The investment revealed the desire for proliferation in the constituents of the middle tier. This was a feature perpetuating the middle tier to make it castelike. An illustration is the following.

The investment in children's schooling - like having them attend different courses and training programs - can cost you as much as $¥ 55,000$ a year (US $\$ 8,052$ or $£ 5,565$ ). (Uncle Lee, 40 , entrepreneur)

\section{Political-economic Coalition}

8.1 A political-economic coalition happened in the connection between entrepreneurs or professionals and cadres. According to the interviewees, the coalition involved networking, socializing, exchange, sharing, gathering, and other social interactions. The coalition emerged from the desire to acquire privileges and operated through gifting.

\section{Desiring privileges}

8.2 Desiring and eventually acquiring privileges were the foundation of political-economic coalition. The privileges, according to the interviewees, meant benefits to the operation of business or professional service to increase rewards. This happened because cadres controlled valuable resources, such as licensing, that facilitated businesses and services to make extraordinary profits. The feature reflected the privilege of the bureaucrats to benefit from marketization and partnership with entrepreneurs. In the following, an interviewee even mentioned privileges to smuggling business.

I got help [from some influential and powerful government officers]. They seemed to have close connections with district offices in Guangdong. Their help made my smuggling business smoother and more lucrative in the postreform era. (Uncle Ho, 49, entrepreneur) 
From cadres' perspective, cadres wielded administrative power and the power and information that were critical to businesses and services. One instance was the business link between private and public sectors, which represented opportunities to benefit economic and political partners. The feature illustrated the commonality of different members within the middle tier to reap joint privileges from their coalitions. A cadre revealed the following explanation.

We cannot earn as much money as entrepreneurs and professionals, but we have certain power. We are not influential cadres like central government officials [she is very powerful cadre at local level], but they need our referrals and information when they do some part-time work or some consultancy work for us. Most of them need our help. (Aunt Jennifer, 53, cadre)

\title{
Gifting
}

8.4 Gifting, as mentioned by interviewees, exchanged money, goods, services, information, and/or other privileges between partners in private and public sectors. It happened on many occasions in China, including birthdays, holidays, and festivals. Moreover, gifting could commonly take the form of a red packet, which was a usual medium to transfer money. This feature indicated the recognized function of gifting to secure social relationships in China. Gifting was an effective way to secure privileges, as mentioned below:

\begin{abstract}
Most of our friends compare how much laisee (award) or red packet money we give to cadres for their birthday, for the birthdays of their family members, for their children's marriages or even for their funerals. The more money you give, the more sincerity you show. (Uncle Moss, 48, entrepreneur)
\end{abstract}

8.5 Gifting nevertheless hinged on the good relationship built in the coalition, according to the interviewees. As such, trustfulness and reliability were essential conditions for gifting. These conditions arose because of distrust among government agencies at municipal, regional, and central levels, which harbored disparate interests. This feature indicated that gifting worked only within trustful political-coalition coalition, as gifting was not blatantly acceptable among strangers. Essentially, there were interlocking agencies and interests that raised caution about gifting. About the intricacy in gifting, an entrepreneur recited the following.

\begin{abstract}
I'm used to maintaining good relationships with regional cadres such as those in the taxation bureau, industry and commerce bureau and license registration bureau. Relationships between professionals and regional cadres are interdependent and intertwined. If a reliable and trustful person isn't introducing you, the regional cadre won't dare to take your red packet and gifts. Regional cadres are now very cautious simply because they don't know your background. They don't know whether you're a spy from the central government or from western countries to test the water or probe the honesty of regional cadres in China. It's useless for you to have in-depth interviews with regional cadres. They won't tell you the truth. (Uncle Fong, 48, entrepreneur)
\end{abstract}

\section{Extravagance Predisposing the Political-economic Coalition}

9.1 Extravagance was likely to predispose the political-economic coalition in order to sponsor the extravagance. Moreover, extravagance was required to prepare gifts to consolidate the political-economic coalition. Hence, extravagance was a means to acquire privileges. This feature reflected the property of dependence on the interchange of economic and social capital and practices. That is, economic capital and practice and social capital and practice needed to buttress each other. A cadre offered the following remark.

I always visit Hong Kong whenever I travel. It's a shopping paradise where I can always buy the most wonderful and beautiful fashions and other products. The most exciting thing I buy is jewellery. In each visit I spend around $¥ 50,000$ [US $\$ 7,322 £ 5,058]$ on diamonds, jade, gold, silver and pearls. Shopping in Hong Kong really makes me go crazy. All the items I buy are gifts for my business partners. I hardly ever buy for myself. (Aunt Jennifer, 53, cadre)

9.2 Cadres afforded extravagance by securing the economic-political coalition of gifting and transferring privileges. As such, gift money provided the economic basis for extravagance, such as enjoying luxury living. This condition illustrated the mutuality of extravagance and privilege. An entrepreneur provided the following observation.

I know many regional cadres who spent $¥ 600,000$ [US\$87,796 or $£ 60,605$ ] purchasing a lychee garden, while others have spent more than $¥ 6$ million [US\$877,960 or $£ 606,050$ ] decorating two three-story houses that are being built nearby. In addition, a dozen gardeners were hired to work in the lychee garden. Some regional cadres have spent RMB 100,000 [around US\$14,631 or $£ 10,004$ ] on providing an access road to the lychee garden, whereas one cadre 
spent more than $¥ 100,000$ on road renovations and repairs such as paving the road with cobblestones. Most of the money came not directly from their salaries, but from red packets that they received in their work. (Uncle Fong, 48, entrepreneur)

\title{
Preserving the Political Structure
}

10.1 Preserving the political structure was preferable, according the interviewees. That is, maintaining the status quo or political stability, rather than urging for democratization, was desirable. Change would be a challenge to privileges enjoyed by the middle tier. This reflection indicated that the middle tier realized the importance of the existing political structure for sustaining the privilege of the tier. A professional provided the explanation as follows.

\footnotetext{
I can safely say that the road to democracy in China is hopeless after I was heavily involved in the June 4th incident when at university twenty years ago. I don't think I can improve the current tense situation and differences that limit the participation of everyone in China. I only want to maintain the status quo after the serious attempt to fight for democracy twenty years ago. To me, change now represents a challenge rather than an opportunity. (Uncle Yang, 40, professional)
}

10.2 Maintaining privileges would be a reason for preserving the political structure, according to the interviewees. As such, enjoying extravagance and reaping privileges from the political-economic coalition were key concerns for the middle tier. This comment reflected the feature of sustaining the viability of middle tier economically and politically. A professional disclosed the concerns in the following quote.

\begin{abstract}
Some foreigners think that we have lost our freedom. I know what the government has done and what they are trying to hide from us. But we won't disturb this peaceful atmosphere. We won't go against the government unless it gives us no space in which to live. With one ruling party it is hard to make any actual change. We can do nothing but take advantage of opportunities for our own advancement [in this globalizing China] .... However, I think China could achieve more in the area of political development now. (Sung, 30, professional)
\end{abstract}

\section{Discussion}

11.1 Findings from interviews with Chinese entrepreneurs, professionals, and cadres substantiate the investment theory about the influences of extravagance on political-economic economic and political preservation. That is, extravagance in terms of conspicuous consumption, luxury living, and investment creates a need for the coalition to generate privileges through gifting, and the coalition is the basis for political preservation. The findings therefore reveal the political-economic coalition as a condition for the Chinese middle tier to support the status quo.

11.2 The investment theory, as a grounded theory informed by ideas provided by the middle tier, tends to build on some factors pertaining to the middle tier and Chinese society. These ideas simply portray the property of the middle tier. First, the middle tier discloses the value of extravagance, luxury living, conspicuous consumption, investment, and acquiring privileges. In other words, the middle tier manifests the orientation toward hedonism, egoism, and privatism in taking care of the interest of one's family. This orientation would in turn rest on individualism arising concomitantly from modernization (Heberer 2009). Essentially, the orientation means that the middle tier is not solidary to pursue its common interests collectively. The constituents of the tier thereby do not form and converge to a class that covers all entrepreneurs, professionals, and cadres. Instead, the tier maintains particularistic coalitions that are competitive and taking advantage of each other. Second, the middle tier is fond of social comparison to rationalize its conspicuous consumption and classy living. The basis of such practices rest on inequality and associated risks escalating in China (Qi and Oberwittler 2009; Zhang and Mo 2005). The inequality and risks in turn originate from marketization to make people competitive and aggressive (Boland 2007). Consequently, the middle tier demands safety, privileges, and differences from others to align with inequality in society. The demand thereby underlies the quest for privileges and extravagance through the political-economic coalition. Third, the middle tier is powerful economically and politically, particularly thanks to the hybrid of the market economy and authoritarian polity (Dittmer and Gore 2001). On the one hand, the private sector of the middle tier is powerful due to the feasibility of using economic capital to acquire labor and other resources in the market. The sector can thereby capitalize on investment to harvest lucrative returns. On the other hand, the public sector of the middle tier is powerful due to its regulation of and intervention into the private sector. Notably, the sector is crucial in endorsing and facilitating contracting to generate privileges to the political-economic coalition. The coalition, therefore, is lucrative and worthwhile for preservation. This explains why those of the middle tier bonded to the coalition lends support to political preservation. Fourth, gifting is a normative practice among Chinese (Kipnis 2002). This norm would thereby normalize gifting as a way of 
networking in political-economic coalition.

11.3 Therefore, the Chinese middle tier is unlikely to form a unitary and solidary class because of competition to maximize privileges in the state-sponsored market economy. Vast industrial, occupational, and regional diversities in China and governmental discourse also prevent the formation of a cohesive middle class (Song and Lee 2010; Heberer 2009). Consequently, entrepreneurs, professionals, and cadres incubate coalitions to acquire their own particularistic privileges. These coalitions also usually operate underground and therefore need to constrain their sizes and inclusiveness. Essentially, if a coalition grew to share benefits among free riders, the benefits would no longer be privileges. Fragmenting the middle tier into exclusive coalitions would also stabilize the political structure, as each coalition is not powerful enough to overthrow the structure (Walder 1995).

11.4 In sum, the investment theory reveals that the Chinese middle tier envisions the investment of economic capital in gifting to sustain social capital based on political-economic coalition in order to reap privileges or economic capital to finance cultural capital and symbolic capital. Here, economic capital involves money and goods, social capital means trustful social relations useful for exchange, cultural capital consists of quality education and superlative lifestyle, and symbolic capital is the social status derived from conspicuous consumption and social comparison (Ibrahim 2011). The middle-tier Chinese, in addition to connecting investment, coalition, and extravagance, espouses the preservation of the political structure in order to perpetuate its privileges.

\section{Limitations and Future Research}

12.1 The study is limited to interviews with selected entrepreneurs, professionals, and cadres in Guangdong to illustrate the middle tier. This means that the study does not exhaust the full reality of life in the tier. The illustration locates only the reality residing in the mind of the middle tier (Donald and Zheng 2009). To grasp the reality completely, future research needs to combine interviewing, observation, and other means to garner subjective and objective data from diverse sources, including people and documents. The present illustration also notably entails corroboration using generalizable and quantifiable data collected from representative samples. Future research is required to verify discoveries from qualitative data. The verification needs to measure extravagance, coalition, and political preservation and analyzes their relationships based on a representative sample of the middle tier. For the verification of the investment theory, moreover, future research needs to incorporate into its analysis measures of the investment motive and belief about the harvest of privileges from political-economic coalition, the value of extravagance, particularly that of luxury living and conspicuous consumption, and the norm of gifting. Future research can also explore the influences of societal inequality and risks on extravagance, coalition, and political preservation. This exploration would involve regional comparisons within China or even other countries in order to examine the generality of findings.

\section{Implications}

13.1 As democratic political reform is imperative to advance economic and political progress and fairness in China (Tian et al. 2007), the implications of the results for the reform are remarkable. The implications reveal that political-economic coalitions in the middle tier of China poses a robust impediment to the reform. This robustness stems from the mutual dependence among extravagant living, privilege derived from the coalitions, and the political structure that sustain the coalitions. Hence, the middle tier is a countervailing force to the reform through its maintenance of the coalitions. The implications echo those about the impediment of political-economic factions to political reform (Chen 2010; Tsai and Dean 2014).

13.2 To enable the reform, conversely, it is necessary to lessen the extravagance, privileges, and coalitions in general and the investment and gifting in particular. This lessening essentially needs to weaken the perpetuation of privileges in the middle tier. Crucially, the investment theory of political-economic coalition clearly indicates the central role of investment in the persistence. To discourage such investment, it is necessary to attenuate the gain from the investment (Brown and Brown 2006). The attenuation entails the curtailing of privileges arising from the coalitions of the middle tier. This implication echoes the policy of the current Chinese administration to repel extravagance and restore thrift (S. Yuen 2014). The policy would pave a straight road to political reform by undercutting privileges accruing to the political-economic coalition. Anyhow, the coalition needs an overhaul to make it virtuous, fair, and benign, rather than extravagant, collusive, and factious (Mele 2010; Su et al. 2006). A promising way for the overhaul is the discouragement of gifting, which also aligns with the new initiative for political practice in China (S.Yuen 2014). 


\section{References}

ANAGNOST, Ann. (2008) 'From class to social strata: Grasping the social totality in reform-era China',Third World Quarterly, Vol. 29, No. 3, p. 497-519. [doi:10.1080/01436590801931488]

ASHWORTH, Peter D. (2013) 'The gift relationship', Journal of Phenomenological Psychology, Vol. 44, No. 1, p. 1-36. [doi:10.1163/15691624-12341243]

BOLAND, Alana. (2007) 'The Trickle-down Effect: Ideology and the Development of Premium Water Networks in China's Cities.' International Journal of Urban \& Regional Research 31 (1) p. 21-40.

BROWN, Stephanie L. and Brown, R. Michael (2006) 'Selective investment theory: Recasting the functional significance of class relationships', Psychological Inquiry, Vol. 17, No. 1, p. 1-29. [doi:10.1207/s15327965pli1701_01]

CHAl, Hongxia and Song, Xiongwei (2013) 'The adaptive state: Understanding political reform in China',Policy Studies, Vol. 34, No. 1, p. 73-88. [doi:10.1080/01442872.2013.766542]

CHEN, Ling (2010) 'Playing the market reform card: The changing patterns of political struggle in China's electric power sector', China Journal, Vol. 64, p. 69-95.

CRABB, Mary W. (2010) 'Governing the middle-class family in Urban China: Educational reform and questions of choice', Economy \& Society, Vol. 39, No. 3, p. 385-402. [doi:10.1080/03085147.2010.486216]

DITTMER, Lowell and Gore, Lance (2001) 'China builds a market culture', East Asia, Vol 19, No. 3, p. 9-50. [doi:10.1007/s12140-001-0009-x]

DONALD, Stephanie Hemelryk and Zheng, Zi (2009) 'Post-Mao, Post-Bourdieu: Class culture in contemporary China', Portal Journal of Multidisciplinary International Studies, Vol. 6, No. 2, p. 1-11.

EBERT, Teresa L. and Zavarzadeh, Mas'ud (2008) Class in Culture. Boulder, CO: Paradigm.

FUMAGALLI, Matteo (2007) 'Framing ethnic minority mobilisation in Central Asia: The cases of Uzbeks in Kyrgyzstan and Tajikistan', Europe-Asia Studies, Vol. 59, No. 4, p. 567-590.

[doi:10.1080/09668130701289869]

GERTH, Karl (2011) 'Lifestyles of the rich and infamous: Creation and implications of China's new aristocracy', Comparative Sociology, Vol. 10, p. 488-507. [doi:10.1163/156913311X590592]

GLAESER, Edward I., Laibson, David and Sacerdote, Bruce (2002) 'An economic approach to social capital', Economic Journal, Vol. 112, p. F437-F458. [doi:10.1111/1468-0297.00078]

GOODMAN, David S. G. (2014) 'Middle class China: Dreams and aspirations', Journal of Chinese Political Sciences, Vol. 19, p. 49-67. [doi:10.1007/s11366-013-9275-x]

GRIFFIN, Christine and Bengry-Howell Andrew (2008) Ethnography in Willig, Carla and Stainton-Rogers, Wendy (Eds.) The Sage Handbook of Qualitative Research in Psychology. Los Angeles, CA: Sage.

GUO, Chun and Miller Jane K. (2010). 'Guanxi dynamics and entrepreneurial firm creation and development in China', Management \& Organization Review, Vol. 6, No. 2, p. 267-291. [doi:10.1111/j.17408784.2010.00180.x]

GUO, Yingjie (2012). 'Classes without class consciousness and class consciousness without classes: The meaning of Class in the People's Republic of China', Journal of Contemporary China, Vol. 21, No. 77, p. 723-739. [doi:10.1080/10670564.2012.684956]

HANLEY, Eric and Treiman, Donald J. (2005) 'Recruitment into the Eastern European communist elite: Dual career paths', Research in Social Stratification \& Mobility, Vol. 23, p. 35-66. [doi:10.1016/S02765624(05)23002-0]

HEBERER, Thomas (2009) 'Evolvement of citizenship in Urban China or authoritarian communitarianism? Neighborhood development, community participation, and autonomy', Journal of Contemporary China, Vol. 18, No. 61, p. 491-515. [doi:10.1080/10670560903033786]

HIMES, Kenneth R. (2007) 'Consumerism and Christian ethics', Theological Studies, Vol. 68, p. 132-153. [doi:10.1177/004056390706800107] 
HOOD, Jane C. (2007) Orthodoxy vs. power: The defining traits of grounded theory in Bryant, Antony and Charmaz, Kathy (Eds.) The Sage Handbook of Grounded Theory. Los Angeles, CA: Sage.

HUNTINGTON, Samuel P. (1968) Political Order in Changing Societies. New Haven, CT: Yale University Press.

IBRAHIM, Joseph (2013) 'The struggle for symbolic dominance in the British anti-capitalist movement field', Social Movement Studies, Vol. 12, No.1, p. 63-80. [doi:10.1080/14742837.2012.666396]

IBRAHIM, Yousaf (2011) 'Political distinction in the British anti-capitalist movement',Sociology, Vol. 45, No. 2, p. 318-334. [doi:10.1177/0038038510394026]

KIPNIS, Andrew (2002) Practices of guanxi: Production and practices of guanxi in Gold, Thomas, Guthrie, Doug and Wank, David (Eds.) Social Connection in China: Institutions, Culture, and the Changing Nature of Guanxi. Cambridge, UK: Cambridge.

LEE, Ching Kwan and Zhang, Yonzhong (2013) 'The power of instability: Unraveling the microfoundations of bargained authoritarianism in China', American Journal of Sociology, Vol. 118, No. 6, p.1475-1508. [doi:10.1086/670802]

LI, He (2006) 'Emergence of the Chinese middle class and its implications',Asian Affairs, Vol. 33, No. 2, p. 67-83.

LIN, Thunghong and Wu, Xiaogang (2009) 'The transformation of the Chinese class structure, 1978-2005',Social Transformations in Chinese Societies, Vol. 5, p. 81-112.

MA, Weihong and Cheng, Joseph Y. S. (2010). 'The evolution of entrepreneurs' social networks in China: Patterns and significance', Journal of Contemporary China, Vol. 19, No. 67, p. 891-911. [doi:10.1080/10670564.2010.508590]

MALLARD, Gregoire (2011) 'The gift revisited: Marcel Mauss on war, debt, and the politics of reparations', Sociological Theory, Vol. 29, No. 4, p. 225-247. [doi:10.1111/j.1467-9558.2011.01398.x]

MELE, Domenec (2010). 'The practice of networking: An ethical approach',Journal of Business Ethics, Vol. 90, p. 487-503.

MILLINGTON, Andrew, Eberhardt, Markus and Wilinson Berry (2006) 'Guanxi and supplier search mechanisms in China', Human Relations, Vol. 59, No. 4, p. 505-531. [doi:10.1177/0018726706065372]

MOLM, Linda D. (2008) The structure of reciprocity and integrative bonds: The role emotions in Clay-Warner, Jody and Robinson, Dawn T. (Eds.) Social Structure and Emotion. San Diego, CA: Academic.

NIEDERBERGER, Anne Arquit (2005) 'Science for Climate change policy-making: Applying theory to practice to enhance effectiveness', Science \& Public Policy, Vol. 32, No. 1, p. 2-16.

[doi:10.3152/147154305781779678]

NORRIS, Pippa (2011) Democratic Deficit: Critical Citizens Revisited. New York: Cambridge University Press.

OPP, Karl-Dieter (2009) Theories of Political Protest and Social Movements: A Multidisciplinary Introduction, Critique, and Synthesis. London: Routledge.

PALTEMAA, Lauri (2007) 'The Democracy Wall Movement, Marxist Revisionism, and the Variations on Socialist Democracy.' Journal of Contemporary China16(53) p. 601-625.

PROUTEAU, Liopel, and Wolff, Francois-Charles (2008) 'On the relational motive for volunteer work',Journal of Economic Psychology, Vol. 29, p. 314-335.

QI, Chenghui and Oberwittler, Dietrich (2009). 'On the road to the rule of law: Crime, crime control, and public opinion in China', European Journal of Crime Policy Research Vol. 15, 137-157. [doi:10.1007/s10610008-9094-3]

QI, Xiaoying (2013) 'Guanxi, social capital theory and beyond: Toward a globalized social science',British Journal of Sociology, Vol. 64, No. 2, p. 308-324. [doi:10.1111/1468-4446.12019]

QIAN, Junxi (2014) 'Performing the public man: cultures and identities in China's grassroots leisure class',City \& Community, Vol. 13, No. 1, p. 26-48. [doi:10.1111/cico.12049]

RUBINI, Lauretta and Barbieri, Elisa (2013) 'Guangdong Province, China: Firms, cities and sectors of excellence', 
RUFFIER, Jean (2010) 'The knowledge of industrial development: The case of Guangdong',Chinese Sociology \& Anthropology, Vol. 42, No. 3, p. 74-86. [doi:10.2753/csa0009-4625420305]

SAWADA, Yasuyuki and Lokshin, Michael (2009) 'Obstacles to school progression in rural Pakistan: An analysis of gender and sibling rivalry using field survey data', Journal of Development Economics, Vol. 88, p. 335347. [doi:10.1016/j.jdeveco.2008.03.002]

SHI, Fayong (2014) 'Improving local governance without challenging the state: The middle class protest in urban China', China: International Journal, Vol. 12, No. 1, 153-162.

SHIPMAN, Alan (2004) 'Lauding the leisure class: Symbolic content and conspicuous consumption', Review of Social Economy, Vol. 62, No. 3, p. 277-289. [doi:10.1080/0034676042000253909]

SKOPEK, Jan, Schulz, Florian and Blossfeld, Hans-Peter (2011) 'Who contacts whom? Educated homophily in online mate selection', European Sociological Review, Vol. 27, No. 2, p. 180-195.

[doi:10.1093/esr/jcp068]

SONG, Geng and Lee, Tracy K. (2010) 'Consumption, class formation and sexuality: Reading men's lifestyle magazines in China', China, Vol., 64, p. 159-177.

STRAUSS, Anselm and Corbin, Juliet (1998) Basics of Qualitative Research: Techniques and Procedures for Developing Grounded Theory. Thousand Oaks, CA: Sage.

SU, Chenting, Mitchell, Ronald K. and Sirgy, M. Joseph. (2006) 'Enabling guanxi management in China: A hierarchical stakeholder model of effective guanxi', Journal of Business Ethics, Vol. 71, p. 301-319.

TIAN, Zhilong, Haitao Gao, and Malcolm Cone (2007) 'A Study of the Ethical Issues of Private Entrepreneurs Participating in Politics in China.' Journal of Business Ethics 80 p. 627-642.

TIAN, Zhilong, Gao, Haitao and Cone, Malcolm (2007) 'A study of the ethical issues of private entrepreneurs participating in politics in China', Journal of Business Ethics, Vol. 80, p.627-642.

TODOROVA, Zdravka (2013) 'Conspicuous consumption as routine expenditure and its place in the social provisioning process', American Journal of Economics \& Sociology, Vol. 72, No. 5, p. 1183-1204. [doi:10.1111/ajes.12039]

TSAI, Wen-Hsuan and Dean, Nicola (2014) 'Experimentation under hierarchy in local conditions: Cases of political reform in Guangdong and Sichuan, China', China Quarterly, Vol. 218, p. 339-358. [doi:10.1017/S0305741014000630]

WALDER, Andrew G. (1995) 'Career mobility and the communist political order', American Sociological Review, Vol. 60, No. 3, p. 309-328. [doi:10.2307/2096416]

WALDER, Andrew G. (2003) 'Elite opportunity in transitional economies', American Sociological Review, Vol. 68, p. 899-916. [doi:10.2307/1519750]

WANG, Cheng Lu and Chen, Zhen Xiong (2004) 'Consumer ethnocentrism and willingness to buy domestic products in a developing country setting: Testing moderating effects', Journal of Consumer Marketing, Vol. 21, No. 6, p. 391-400. [doi:10.1108/07363760410558663]

WANG, Ning (2012) The Rise of the Consumer in Modern China Reading, UK: Paths International.

WEEDE, Erich (2010) 'The rise of India: Overcoming caste society and permit-license-quota raj, implementing some economic freedom', Asian Journal of Political Science, Vol. 18, No. 2, p. 129-153. [doi:10.1080/02185377.2010.492977]

WIELOCH, Neil (2002) 'Collective mobilization and identity form the underground: The deployment of oppositional capital in the harm reduction movement', Sociological Quarterly, Vol. 43, No. 1, p. 43-72.

XIANG, Lin, and Li, Shi (2001) New trends in income distribution in Jiang, Liu, Lu, Xueyi and Dan, Tianlun (Eds.) 2000: Analysis and Forecast of China's Social Situation. Beijing, China: China Social Science.

XIE, Yu and Wu, Xiaogang (2008) 'Danwei profitability and earnings inequality in urban China',China Quarterly, Vol. 195, p. 558-581. 
YANG, Yiana, Williamson, John B. and Shen, Ce (2010) 'Social security for China's rural aged: A proposal based on a universal non-contributory pension', International Journal of Social Welfare, Vol. 19, p. 236-245. [doi:10.1111/j.1468-2397.2009.00658.x]

YAO, Shuntian (2002) 'Privilege and corruption: The problem of China's socialist market economy',American Journal of Economics \& Sociology, Vol. 61, No. 1, p. 279-299. [doi:10.1111/1536-7150.00160]

YU, Hong (2014) 'Industrial upgrading in Guangdong: How well is it performing', China: International Journal, Vol. 12, No. 1, p. 108-131.

YUEN, Samson (2014) 'Disciplining the party', China Perspectives, Vol. 2014, No. 3, p. 41-47.

ZHANG, Liwen and Mo, Gen (2005) Circumstances of Harmony: Study of Change and Chinese Culture Beijing, China: People.

ZHANG, Marina Yue with Stening, Bruce W. (2010)China 2.0: Transformation of an Emerging Superpower and the New Opportunities. Singapore: Wiley.

ZHENG, Shiping (2003) 'Leadership change, legitimacy, and party transition on China', Journal of Chinese Political Science, Vol. 81, No. 1, p. 47-63.

ZIMMERMANN, Ekkart (1983) Political Violence, Crises, and Revolutions: Theories and Research Cambridge, MA: Schenkman. 